\title{
Structural Neuroimaging of Concomitant Depressive Symptoms in Amnestic Mild Cognitive Impairment: A Pilot Study
}

\author{
Jean-François Morin ${ }^{\mathrm{a}} \quad$ Abderazzak Mouiha $^{\mathrm{a}}$ \\ Sandra Pietrantonio ${ }^{d}$ Simon Duchesne ${ }^{a, c}$ Carol Hudon $^{a, b}$ \\ ${ }^{a}$ Centre de recherche de l'Institut universitaire en santé mentale de Québec, ${ }^{\text {b École de }}$ \\ psychologie and ${ }^{\mathrm{C}}$ Département de radiologie, Université Laval, Québec, Qué., and ${ }^{\mathrm{d}} \mathrm{McGill}$ \\ Centre for Studies in Aging, Faculty of Medicine, McGill University, Verdun, Qué., Canada
}

\section{Key Words}

Aging • Alzheimer's disease - Depression • Entorhinal cortex · Hippocampus - Mild cognitive impairment $\cdot$ Prodromal phase $\cdot$ Magnetic resonance imaging $\cdot$ Medial temporal lobe

\begin{abstract}
Late-life depression (LLD) and amnestic mild cognitive impairment (aMCl) can both denote prodromal Alzheimer's disease. While the two concepts share common clinical features, differential diagnosis between them is crucial. The objective of this pilot study was to explore differences in terms of the hippocampal $(\mathrm{HC})$ and entorhinal cortex $(\mathrm{EC})$ volume reduction between LLD and $\mathrm{aMCl}$ patients with (aMCl/D+ group) or without (aMCl group) depressive symptoms. Six LLD, $6 \mathrm{aMCl}$, and $6 \mathrm{aMCl} / \mathrm{D}+$ participants were assessed using a structural magnetic resonance imaging protocol. Manual segmentation of $\mathrm{HC}$ and EC was carried out. The results of volumetric comparisons suggest that the $\mathrm{HC}$ was larger in $\mathrm{aMCl} / \mathrm{D}+$ and LLD subjects compared to aMCl participants. The left EC mean volume was slightly lower in aMCI/D+ subjects. Power analyses revealed that 36 participants per group would suffice to confirm these findings. Overall, these pilot findings suggest that aMCl can be distinguished from LLD based on cerebral atrophy measures, and that $\mathrm{HC}$ and $\mathrm{EC}$ atrophy in $\mathrm{aMCl}$ varies according to the presence or absence of depressive symptoms.

Copyright $\odot 2012$ S. Karger AG, Basel
\end{abstract}




\section{Introduction}

Alzheimer's disease $(\mathrm{AD})$ has become a major public health issue, given that age is a primary risk factor and life expectancy is increasing in developed countries worldwide [1]. There is evidence that $\mathrm{AD}$ pathophysiological processes begin years before the diagnosis of clinical dementia [2]. Consequently, much research has focused on the transitional state between normal aging and early AD [3-5], often referred to as prodromal AD. Findings have shown that prodromal AD can be identified in older adults with amnestic mild cognitive impairment (aMCI) or patients with late-life depression (LLD).

The concept of aMCI generally applies to older adults showing cognitive decline that is greater than that expected for age and education level. Specifically, persons with aMCI present a cognitive complaint and show impaired episodic memory (with or without deficit in another cognitive domain) as indicated by age- and education-stratified norms. As a rule, cognitive symptoms are not severe enough to meet the criteria for dementia or to significantly interfere with activities of daily living [6,7]. Nevertheless, several studies showed that aMCI is closely related to AD. In fact, it is generally assumed that elders with aMCI have approximately a tenfold increased risk of developing AD compared to healthy older adults $[7,8]$.

LLD refers to a mood disorder occurring in aging, the diagnosis of which is generally based on DSM-IV-TR [9] criteria for major depressive episode. LLD encompasses both lateonset and early-onset cases [10]. The neuropsychiatric symptoms of this syndrome can include depressed mood, anhedonia, sleep disturbances, psychomotor agitation or retardation, fatigue or loss of energy, feeling of worthlessness or guilt, diminished ability to think, and thoughts of death. Many patients with LLD also have cognitive deficits, and these can affect episodic memory, executive functions, information processing speed, and visuospatial skills $[11,12]$. Similar to aMCI, research has shown that LLD is associated with subsequent dementia [13]. More precisely, Byers and Yaffe [14] reported that, of 12 prospective studies, 6 found evidence supporting a two- to fivefold increased risk of dementia associated with LLD [15-20].

There are several associations between aMCI and LLD. As mentioned above, both conditions may denote prodromal AD. Further, beside their cognitive deficits, up to $75 \%$ of elders with aMCI have concomitant neuropsychiatric symptoms, the most prevalent being depression, apathy, anxiety, irritability, and sleep disturbances [21, 22]. In addition, persons with aMCI or LLD may have similar cognitive and neuropsychiatric symptoms. That being said, differential diagnosis between aMCI and LLD is imperative because the pathophysiological mechanisms involved in each syndrome likely differ [10]. Surprisingly, and as emphasized by experts convened by the National Institute of Mental Health [23], investigations of these conditions have long proceeded along separate tracks; thus, there is a crucial need to carry out more studies comparing aMCI and LLD patients. These kinds of studies will help clarifying the common and distinct mechanisms involved in these two conditions [23], and this, in turn, will put forward some sources of heterogeneity of the prodromal phase of AD.

Some authors attempted to differentiate the cognitive profile of aMCI and LLD patients. Research on this topic revealed that, to some extent, LLD patients can encode, consolidate, and recognize items, but their self-retrieval processes are significantly impaired [24]. On the other hand, the memory impairment in persons with aMCI alters virtually all memory processes [25]. Overall, the phenotypic differences that were evidenced in previous studies suggest the existence of distinct underlying pathophysiological mechanisms between aMCI and LLD syndromes. More precisely, considering that memory processes are not equally affected in aMCI and LLD, there could be differences between these conditions regarding the integrity of medial temporal lobe (MTL) structures. A recent literature review has revealed that no study has yet addressed this issue [26]. 
Morin et al.: Structural Neuroimaging of Concomitant Depressive Symptoms in Amnestic Mild Cognitive Impairment: A Pilot Study

Besides the need for studies comparing aMCI and LLD patients, it is also necessary to clarify the role of depressive symptoms in older adults meeting the aMCI criteria. At this time, it is uncertain whether aMCI with concomitant depressive symptoms (aMCI/D+) should be considered as subclinical LLD or if it corresponds to a particular aMCI condition with higher risk of progression to $\mathrm{AD}[10,27]$. This question can hardly be answered as most previous studies on aMCI excluded persons with aMCI/D+. Thus, knowledge on the nosological status of elders with aMCI/D+ is actually very scarce. Systematic investigation of these patients and their comparison with LLD or aMCI patients with no, or few, depressive symptoms (hereafter named aMCI) could help clarifying the importance of assessing depressive symptoms in the diagnosis of prodromal $\mathrm{AD}$ [23].

Two studies have demonstrated that depression was a potentially useful clinical marker for identifying MCI subjects who are more likely to progress to $\mathrm{AD}[28,29]$. To date, however, few studies compared aMCI and aMCI/D+ patients. One work revealed that the risk of developing $\mathrm{AD}$ is doubled in persons with $\mathrm{aMCI} / \mathrm{D}+$ compared to their aMCI counterparts [30]. A recent 2-year study revealed that subjects with aMCI/D+ stable over time demonstrated a decline on select neuropsychological tests and had higher rates of conversion to AD (62\%) compared with stable aMCI subjects [31]. At the semiological level, our studies revealed that aMCI and aMCI/D+ subgroups can be distinguished from each other on tasks assessing episodic memory, semantic memory, and executive functions [32, 33]. An important question is whether the differences between the episodic memory impairment of aMCI/D+ and aMCI patients are associated with neurobiological differences. A related question is to what extent aMCI/D+ and LLD are similar or different from a neurobiological perspective.

Neuroimaging could further elucidate the underlying neurobiological correlates of aMCI, aMCI/D+, and LLD semiology. The strong correlation between MTL volumes and episodic memory performance is well known [34]. Furthermore, the earliest AD-associated brain alterations, according to histopathological staging [35], occur in MTL structures such as the hippocampus (HC) and the entorhinal cortex (EC). Atrophy of HC and EC is present in aMCI patients [36-40] and has been associated to memory loss in these subjects [36, 37, 41]. In aMCI, the HC helps predicting progression to dementia [37, 42]. However, the EC is a better predictor of $\mathrm{AD}$-related neurodegeneration [36, 43, 44]. In comparison to the $\mathrm{HC}$, the EC appears to be less affected by normal aging [45]. The EC thus is a crucial structure to evaluate. In LLD subjects, atrophy of HC has also been documented [46], but no study measured the EC volume in these patients yet [47].

It is important to emphasize that all magnetic resonance imaging (MRI) studies assessing MTL volumes in aMCI or LLD have been conducted independently. Thus, it is difficult to estimate whether or not the degree of $\mathrm{HC}$ and atrophy is comparable between aMCI and LLD patients. Furthermore, to our knowledge, no study has evaluated EC atrophy in LLD and $\mathrm{aMCI} / \mathrm{D}+$. Taking into consideration that the $\mathrm{EC}$ is a better predictor of cognitive decline than the HC $[48,49]$, it could represent an opportunity to differentiate prodromal AD syndromes, especially as neuropsychological differences exist between them. Henceforth, there exist no comparative MRI data between these groups. As the neurobiological mechanisms relating to depression and cognitive impairment in older adults are poorly understood [23], it is critical to obtain accurate biomarker data such as the HC and EC to compare aMCI, aMCI/D+, and LLD patients. Differentiating these subgroups at high risk of developing dementia at the neurobiological level could help in the development (or adaptation) of more personalized pharmacological and non-pharmacological therapies [50].

The principal objective of this study is to investigate differences in $\mathrm{HC}$ and $\mathrm{EC}$ volumes between aMCI, aMCI/D+, and LLD individuals. We hypothesized that $\mathrm{HC}$ and EC volumes were less reduced in aMCI/D+ and LLD versus aMCI patients as aMCI/D+ appears to be closer to LLD and aMCI closer to AD from a nosological point of view. In this article, we re- 
port our results from a pilot study aimed at providing evidence towards larger-scale feasibility. Our secondary objective is to formulate recommendations in order to improve the design of future MRI studies in aMCI, aMCI/D+, and LLD populations.

\section{Methods}

\section{Participants}

This study included 6 aMCI, 6 aMCI/D+, and 6 LLD patients. All subjects gave informed written consent to participate in the study. The Ethics Research Committee of the Institut universitaire en santé mentale de Québec approved the study.

Experienced clinicians (general practitioners, neurologists, geriatricians, or psychiatrists) from Québec City (Qué., Canada) referred the patients. The diagnoses of aMCI or LLD were made by the referring clinician and confirmed by the research team based on the results from clinical and cognitive instruments (see below).

Participants were 59-80 years old and their mother tongue was French. Patients with LLD were diagnosed using the DSM-IV-TR [9] criteria for major depression disorder. Participants from the aMCI and aMCI/D+ groups all met the following criteria for single- or multipledomain aMCI as proposed by Petersen [6]: (1) memory complaint, preferably corroborated by an informant; (2) objective memory impairment for age; (3) essentially preserved general cognitive function; (4) largely intact functional activities, and (5) not demented. None of the participants had dementia based on clinical assessment and the referring clinician judgment. The two aMCI subgroups were identified based on the participants' score on the Geriatric Depression Scale (GDS) [51]. In aMCI, the GDS is a reliable screening tool for depression, with sensitivity and specificity values of 95 and $67 \%$, respectively, when a cut-off score of 8 is applied [52]. We identified participants as having aMCI/D+ if they had a score of 8 or more on the GDS. Participants were identified as aMCI (with few or no depressive symptoms) when the GDS score was below 8. Finally, one must note that in the current study depression in aMCI/ $\mathrm{D}+$ patients was subclinical (i.e. it did not meet any DSM-IV mood disorder criteria).

For all participants, the exclusion criteria were: (1) history of traumatic brain injury; (2) presence of significant vascular risk factors (i.e. score higher than 7 on the Hachinski scale [53]); (3) former intracranial surgery; (4) history of neurological disorder of cerebral origin, including dementia, or associated with another demented state (e.g. multiple sclerosis, parkinsonism, frontotemporal dementia); (5) unstable metabolic or medical condition (e.g. uncontrolled diabetes, hypothyroidism); (6) general anesthesia in the last 12 months, and (7) contraindications to MRI. A specific exclusion criterion for aMCI/D+ and aMCI was a history or actual diagnosis of major depression disorder [9].

During the study, aMCI participants took neither antidepressants nor benzodiazepines. Antidepressants were taken by $5 \mathrm{aMCI} / \mathrm{D}+$ subjects $(3$ selective serotonin reuptake inhibitor, 1 serotonin-norepinephrine reuptake inhibitor, and 1 serotonin antagonist and reuptake inhibitor) and 5 LLD subjects (4 selective serotonin reuptake inhibitor and 1 tricyclic antidepressant). Benzodiazepines were taken only by $1 \mathrm{aMCI} / \mathrm{D}+$ and 2 LLD subjects. Antipsychotic medication was taken by 1 LLD participant.

\section{Neuropsychological and Clinical Assessment}

Senior neuropsychology research assistants, supervised by one of the authors (C.H.), evaluated the participants over a 120 -min session to provide quantification of clinical characteristics, cognitive functioning, and functional status.

Following a semi-structured interview to document medical history, drug prescriptions, and sociodemographic data, we used the Montreal Cognitive Assessment (MoCA) [54] to 
evaluate general cognitive functioning. The Hachinski ischemic scale [53] was used to assess vascular risk factors. We administered the Questionnaire de plainte cognitive [55] and the GDS [51] to assess cognitive complaints and depressive symptoms, respectively. We examined episodic memory using the Rappel libre/rappel indicé à 16 items [56], a free/cued word recall test used as a measure of verbal learning in French-speaking populations; the procedure of the Rappel libre/rappel indicé à 16 items is similar to the Free and Cued Selective Reminding Test [57]. Visuoconstructional abilities were evaluated by the copy of the Rey-Osterrieth Complex Figure Test [58], and early visuoperceptual processes were assessed with the size-match task of the Birmingham Object Recognition Battery [59]. Subjects also performed the Coding subtest of the Wechsler Adult Intelligence Scale [60] to estimate information processing speed. To examine language capabilities, participants performed a verbal fluency task using Letter (T-N-P) and Category (animals) conditions [61] as well as the 15-item version of the Boston Naming Test [62]. Semantic memory and executive functions were assessed using the picture version of the Pyramids and Palm Trees Test [63] and the California Stroop Test [64], respectively. Finally, participants were administered the Alzheimer's Disease Cooperative Study Activities of Daily Living Inventory [65] to measure activities of daily living.

\section{MRI Protocol}

One aMCI/D+ patient was diagnosed with $\mathrm{AD}$ by a medical doctor 2 months after his MRI examination. This participant was not excluded from this study because he was still considered in the prodromal phase of $\mathrm{AD}$ at the time of the MRI exam.

All MR images were acquired on a 3.0-Tesla Phillips at IRM Québec in Québec City (Qué., Canada). A standardized ADNI imaging protocol [66], including T1-weighted 3D MPRAGE sagittal volumetric acquisition (repetition time $69 \mathrm{~ms}$, echo time $3.13 \mathrm{~ms}$, flip angle $8^{\circ}$, slice thickness $1 \mathrm{~mm}$, in-plane size $1 \times 1 \mathrm{~mm}$, no inversion, whole head coverage), was used. We co-registered the images to the ICBM152 pseudo-Talairach template space [67]. Then, an experienced tracer (S.P.) manually segmented the HC and EC on coronal slices using validated protocols by Pruessner et al. $[68,69]$. The operator was blinded to all clinical data and diagnostic categories. Reported inter- and intrarater intraclass reliability coefficients for this protocol are as follows: right HC 0.94/0.91, left HC 0.86/0.94, right EC 0.93/0.91, and left EC 0.95/0.96.

\section{Statistical Analyses}

We performed statistical analyses using SAS 9.2 for Windows (SAS/STAT and SAS/ Graph software; SAS, Cary, N.C., USA). First, parametric testing (ANOVA) was done to compare the sociodemographic and clinical characteristics of the aMCI, aMCI/D+, and LLD groups, and was further confirmed by non-parametric testing (Wilcoxon). Second, we considered a one-way ANOVA (parametric and non-parametric) design to evaluate volumetric differences of the left and right HC and EC between the groups. Third, in order to study the effect of certain variables on volumetric measurements, we used a regression model. The fitted model was: $\hat{Y}=b_{0}+b_{1}$.age $+b_{2}$.education $+b_{3}$.hachinsk $i+b_{4} \cdot$ sex, where $b_{0}, b_{1}, b_{2}, b_{3}$, and $b_{4}$ are the estimated regression coefficients. Variables in this model (i.e. age, education, Hachinski score, and sex) were included because of their significant impact on HC and EC volumetry. Given the small number of subjects, we used classical and bootstrap regression. For bootstrap regression, a model based on 10,000 re-sample drawings with replacement from the original data was created to estimate regression coefficients. We then obtained predicted and residual values from both classical and bootstrap regressions. Finally, within the framework of a pilot study, we calculated the number of subjects necessary to detect significant differences between groups using an alpha value of $5 \%$ and a nominal power of $80 \%$. 
Table 1. Means \pm SD and significance levels of the demographic and clinical characteristics of the participants

\begin{tabular}{|c|c|c|c|c|}
\hline Measure & $\begin{array}{l}\mathrm{aMCI} \\
(\mathrm{n}=6)\end{array}$ & $\begin{array}{l}\mathrm{aMCI} / \mathrm{D}+ \\
(\mathrm{n}=6)\end{array}$ & $\begin{array}{l}\text { LLD } \\
(\mathrm{n}=6)\end{array}$ & $\begin{array}{l}\mathrm{p} \\
\text { value }\end{array}$ \\
\hline \multicolumn{5}{|l|}{ Participant characteristics } \\
\hline Gender (female/male) & $1 / 5$ & $5 / 1$ & $5 / 1$ & 0.023 \\
\hline Age, years & $70.7 \pm 3.3$ & $71.7 \pm 7.7$ & $71.5 \pm 8.0$ & 0.962 \\
\hline Education, years & $16.0 \pm 5.0$ & $13.3 \pm 5.6$ & $15.8 \pm 4.3$ & 0.557 \\
\hline \multicolumn{5}{|l|}{ Depressive symptoms } \\
\hline GDS & $4.8 \pm 1.9^{\mathrm{b}, \mathrm{c}}$ & $11.2 \pm 1.5^{\mathrm{a}}$ & $14.2 \pm 4.3^{\mathrm{b}}$ & 0.00 \\
\hline \multicolumn{5}{|l|}{ IADLs } \\
\hline ADCS-ADL patients & $40.0 \pm 2.8$ & $41.0 \pm 2.7$ & $38.40 \pm 3.05$ & 0.492 \\
\hline ADCS-ADL caregivers & $62.5 \pm 3.5$ & $56.2 \pm 10.1$ & $60.8 \pm 5.2$ & 0.586 \\
\hline \multicolumn{5}{|l|}{ Vascular risk factors } \\
\hline Hachinski & $1.7 \pm 2.0$ & $1.5 \pm 1.4$ & $2.5 \pm 0.8$ & 0.597 \\
\hline \multicolumn{5}{|l|}{ General cognitive state } \\
\hline \multirow{2}{*}{\multicolumn{5}{|c|}{ Executive functions }} \\
\hline & & & & \\
\hline Stroop D-KEFS (errors) & $1.7 \pm 2.2$ & $3.2 \pm 4.7$ & $1.7 \pm 1.9$ & 0.649 \\
\hline \multicolumn{5}{|l|}{ Information processing speed } \\
\hline Digit Symbol score (WAIS-III) & $56.7 \pm 16.7$ & $47.2 \pm 13.7$ & $49.3 \pm 15.5$ & 0.546 \\
\hline \multicolumn{5}{|l|}{ Visuoconstruction } \\
\hline Rey-Osterrieth Complex Figure copy score & $28.5 \pm 5.4$ & $28.7 \pm 5.5$ & $31.2 \pm 3.6$ & 0.619 \\
\hline \multicolumn{5}{|l|}{ Language } \\
\hline Boston Naming Test score (15 items) & $13.0 \pm 1.3$ & $12.0 \pm 1.4$ & $12.3 \pm 1.75$ & 0.512 \\
\hline Lexical evocation & $33.0 \pm 10.6$ & $23.8 \pm 6.5$ & $32.5 \pm 9.5$ & 0.223 \\
\hline Semantic evocation & $14.8 \pm 6.0$ & $14.8 \pm 2.3$ & $13.8 \pm 6.2$ & 0.928 \\
\hline \multicolumn{5}{|l|}{ Semantic memory } \\
\hline Pyramids and Palm Trees Test & $48.7 \pm 1.9$ & $48.0 \pm 2.2$ & $49.0 \pm 1.3$ & 0.659 \\
\hline \multicolumn{5}{|l|}{ Episodic memory } \\
\hline RL/RI-16 free recall ${ }^{1}$ & $6.5 \pm 3.2$ & $5.4 \pm 2.3$ & $8.9 \pm 2.1$ & 0.089 \\
\hline RL/RI-16 total recall ${ }^{2}$ & $11.3 \pm 3.6$ & $11.7 \pm 1.7$ & $14.1 \pm 2.5$ & 0.205 \\
\hline RL/RI-16 delayed free recall & $5.7 \pm 4.4$ & $6.2 \pm 2.0$ & $9.8 \pm 2.7$ & 0.078 \\
\hline RL/RI-16 total delayed recall & $11.5 \pm 4.9$ & $11.8 \pm 2.2$ & $14.3 \pm 1.8$ & 0.284 \\
\hline
\end{tabular}

IADLs = Instrumental activities of daily living; ADCS-ADL = Alzheimer's Disease Cooperative StudyActivities of Daily Living Inventory; WAIS-III = Wechsler Adult Intelligence Scale-third edition; RL/RI16 = épreuve de rappel libre/rappel indicé à 16 items. ${ }^{1}$ This score was calculated as the mean number of words retrieved over the three free-recall trials. ${ }^{2}$ This score was calculated as the mean total number of words retrieved on all free-recall plus cued-recall trials.

${ }^{\mathrm{a}} \mathrm{p}<0.05$ compared to aMCI; ${ }^{\mathrm{b}} \mathrm{p}<0.05$ compared to aMCI/D+; ${ }^{\mathrm{c}} \mathrm{p}<0.05$ compared to LLD.

\section{Results}

\section{Sample Characteristics}

Table 1 reports the means $( \pm S D)$ and significance levels of the demographic and clinical characteristics of the participants. The groups did not differ regarding age and education level. The aMCI/D+ and LLD groups did not differ in sex distribution (5 women vs. 1 man) but did differ from the aMCI group (5 men vs. 1 woman). As expected, GDS scores were significantly higher in LLD and aMCI/D+ subjects than in aMCI participants ( $\mathrm{p}=0.0001)$. With regard to instrumental activities of daily living and vascular risk factors (Hachinski score), all three groups were similar. Participants with LLD had a higher mean MoCA score 


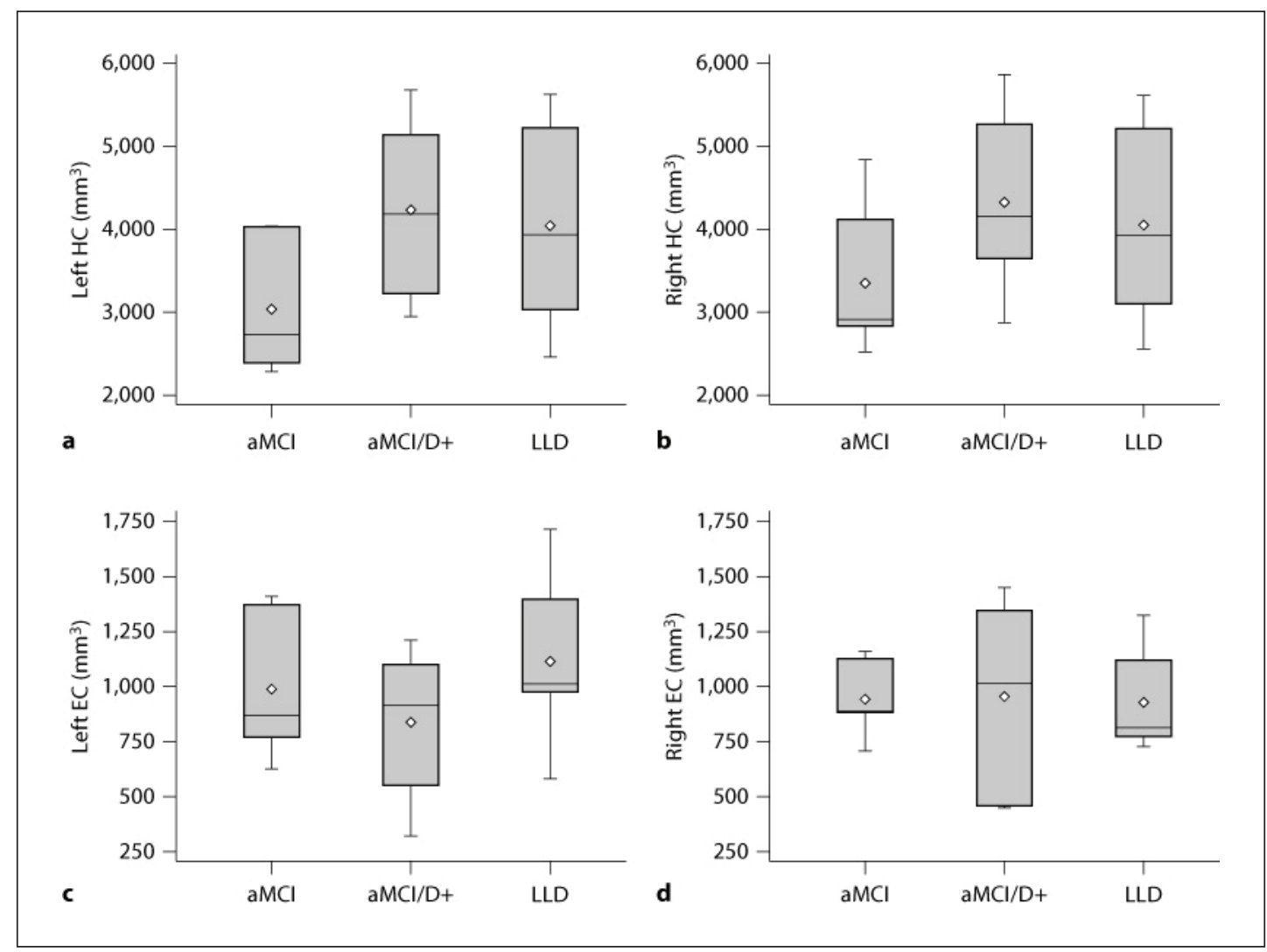

Fig. 1. Boxplots of mean $\mathrm{HC}$ and $\mathrm{EC}$ volumes. a Boxplots of mean right $\mathrm{HC}$ volumes. b Boxplots of mean left $\mathrm{HC}$ volumes. $\mathbf{c}$ Boxplots of mean left EC volumes. $\mathbf{d}$ Boxplots of mean left EC volumes.

compared to aMCI and aMCI/D+ participants ${ }^{1}$. However, the groups did not differ in executive, information processing speed, visuoconstructive, language, and memory (semantic, episodic) measures.

\section{Volumetric Measurements}

Figure 1 depicts the mean $( \pm S D)$ volumes (in $\mathrm{mm}^{3}$ ) of the left (fig. 1a) and right (fig. 1b) $\mathrm{HC}$, and left (fig. 1c) and right (fig. 1d) EC in aMCI, aMCI/D+, and LLD patients. Inspection of data indicates that the left $\mathrm{HC}$ was smaller in aMCI patients $(3,039 \pm 794)$ than in aMCI/ $\mathrm{D}+(4,232 \pm 1,063)$ and LLD $(4,041 \pm 1,290)$ patients. Similarly, the right HC was smaller in aMCI patients $(3,357 \pm 905)$ than in $\mathrm{aMCI} / \mathrm{D}+(4,327 \pm 1,084)$ and $\operatorname{LLD}(4,058 \pm 1,236)$ patients. The mean left EC volume was slightly lower in aMCI/D+ patients $(838 \pm 336)$ compared to aMCI $(987 \pm 330)$ and LLD $(1,118 \pm 390)$ patients, whereas the mean right EC volume appeared to be approximately equal between aMCI/D+ (957 \pm 447$)$, aMCI (943 \pm 170$)$, and LLD (927 \pm 240$)$ patients (table 2).

The one-way ANOVAs (parametric and non-parametric) did not reveal any group effect regarding the different volumetric measurements $\left(\mathrm{F}_{2,15 \mathrm{LHC}}=2.16, \mathrm{p}=0.150 ; \mathrm{F}_{2,15 \mathrm{RHC}}=1.28\right.$,

1 The MoCA total score was not included in the fitted regression model (results below). By adding the MoCA to the other independent variables (age, sex, education, and Hachinski score), we obtained a palue higher than 0.85 . Moreover, when a stepwise regression was applied, the MoCA was not retained as an important variable for its impact on HC and EC volumes. 
Table 2. Mean volumes ( \pm SD) of MTL structures of interest (in $\mathrm{mm}^{3}$ )

\begin{tabular}{lccc}
\hline Volume & aMCI & aMCI/D+ & \multicolumn{1}{l}{ LLD } \\
\hline LHC & $3,039.2 \pm 794.2$ & $4,232.7 \pm 1,063.0$ & $4,041.8 \pm 1,289.5$ \\
RHC & $3,357.2 \pm 905.0$ & $4,326.5 \pm 1,083.9$ & $4,058.3 \pm 1,236.0$ \\
LEC & $987.2 \pm 329.7$ & $838.2 \pm 336.2$ & $1,117.8 \pm 390.0$ \\
REC & $943.2 \pm 170.2$ & $956.7 \pm 447.1$ & $926.8 \pm 239.7$ \\
\hline
\end{tabular}

LHC $=$ Left HC; RHC $=$ right HC; LEC $=$ left EC; REC $=$ right EC.

Table 3. Necessary number of subjects to detect a significant difference between groups given an alpha level of $5 \%$ and a nominal power of $80 \%$

\begin{tabular}{llllr}
\hline Variable & Alpha & Nominal power & Power & Size \\
\hline LHC & 0.05 & 0.80 & 0.889 & 54 \\
RHC & 0.05 & 0.80 & 0.807 & 72 \\
LEC & 0.05 & 0.80 & 0.852 & 108 \\
REC & 0.05 & 0.80 & 0.801 & 6,192 \\
\hline
\end{tabular}

LHC = Left HC; RHC = right HC; LEC = left EC; REC $=$ right EC.

$\left.\mathrm{p}=0.307 ; \mathrm{F}_{2,15 \mathrm{LEC}}=0.94, \mathrm{p}=0.411 ; \mathrm{F}_{2,15 \mathrm{REC}}=0.01, \mathrm{p}=0.986\right)$. Using the $\mathrm{t}$ test, a gender effect was found for the left and right $\mathrm{HC}\left(\mathrm{t}_{2}=3.07, \mathrm{p}=0.007 ; \mathrm{t}_{2}=2.79, \mathrm{p}=0.013\right)$ but not for the left and right EC. Moreover, a classical regression did not reveal any significant association between independent variables (groups) and volumetric measurements; this was further confirmed by bootstrap regression, i.e. the probability of obtaining a significant association using multiple estimates coming from the same distribution was not significant.

\section{Sample Sizes}

Within the framework of a pilot study, we estimated the number of subjects needed to detect significant volumetric differences between groups using an alpha value of 5\% and a nominal power of $80 \%$ (table 3 ). We found that the group size (i.e. total number of aMCI, aMCI/D+, and LLD participants) for left and right $\mathrm{HC}$ measurements should be at least 54 and 72, respectively. For left and right EC volume measurements, 108 and 6,192 participants should be recruited, respectively. In other words, results above should be confirmed with 36 participants per group.

\section{Discussion}

As emphasized in the Introduction, there is a need to elucidate the common and distinct mechanisms involved in aMCI and LLD [23]. It is also important to investigate aMCI/D+ patients more systematically because there is uncertainty whether these individuals actually present subclinical LLD or if they correspond to a particular aMCI subtype [10,27]. With these considerations in mind, the present study aimed to provide preliminary evidence of differences in HC and EC volumes between aMCI, aMCI/D+, and LLD patients. Given the pilot status of the study, volume differences between groups did not reach statistical signifi- 
Morin et al.: Structural Neuroimaging of Concomitant Depressive Symptoms in Amnestic Mild Cognitive Impairment: A Pilot Study

cance. Nonetheless, we observed a smaller HC volume in aMCI than in aMCI/D+ and LLD patients, which was in accordance with our hypothesis. Regarding the EC volume, the left EC was slightly smaller in aMCI/D+ compared to LLD patients, while no right EC volume difference was apparent between the groups. In the future, these findings will need to be confirmed with larger sample sizes (i.e. 36 participants per group).

Hippocampal atrophy was less important in subjects with depression features (aMCI/ $\mathrm{D}+$ and LLD groups) compared to those with no, or few, depressive symptoms (aMCI group). This finding corroborates previous studies that investigated the association between depressive symptoms and episodic memory impairment in older adults at risk of developing AD $[32,70]$. That is to say, knowing that episodic memory in aMCI/D+ patients is somewhat less severely impaired than in aMCI patients [32], and bearing in mind that virtually all memory processes are altered in aMCI [25] but not in LLD [24], it was not surprising to find less HC atrophy in aMCI/D+ and LLD subjects compared to aMCI patients. A recent study using tensor-based morphometry showed that aMCI/D+ patients exhibited significantly more frontal, parietal, and temporal white matter atrophy bilaterally over 2 years compared with aMCI subjects [31]. This could be a result of separate degenerative processes that would corroborate the clinical phenotype.

The EC volume was not largely investigated in the literature on prodromal AD. In fact, our previous literature review [26] identified only 3 aMCI studies providing data for lateralized EC volumes [36, 71,72], and no LLD studies has evaluated EC atrophy. Thus, to our knowledge, the present work is in fact the first to investigate EC volumetry in LLD. Interestingly, the left EC appeared to have a lower mean volume in aMCI/D+ subjects compared to aMCI and LLD subjects, while the right EC volume appeared to be approximately equal between all groups. Again, these findings need to be confirmed with larger samples. Investigation of the EC volume should be of use in studies interested in the differentiation of pre-AD syndromes knowing the $\mathrm{EC}$ is a better predictor of $\mathrm{AD}$-related neurodegeneration $[36,43$, $44]$ and of cognitive decline than the $\mathrm{HC}[48,49]$.

The fact that HC and EC volumes differed between groups underlines the variability of prodromal AD biomarkers. These preliminary differences could rely on various complex mechanisms. For instance, multiple biological pathways potentially link depression to dementia neuropathology, such as vascular disease, alterations in glucocorticoid levels and hippocampal atrophy, increased deposition of amyloid- $\beta$, inflammatory changes, and deficits of nerve growth factors or neurotrophins [14]. Further longitudinal work is necessary to elucidate these mechanisms in relation to $\mathrm{AD}$ development.

From a nosological point of view and based only on the present $\mathrm{HC}$ volume data, one could argue that aMCI/D+ is closer to LLD than aMCI. However, the left EC data and previous neuropsychological findings [33] suggest that the semiology and pathophysiology of aMCI/D+ differ from those of LLD. Of note, our neurobiological findings and previous neuropsychological data [32] also suggest the importance of considering aMCI/D+ as a separate entity from aMCI. In the latter group, the more important $\mathrm{HC}$ atrophy could be accounted for by particular pathophysiological mechanisms (e.g. higher deposition of amyloid- $\beta$ in aMCI compared to aMCI/D+ patients). Of course, this hypothesis remains speculative at this point. Nevertheless, we believe that our findings provide satisfactory evidence to support further investigations on that matter. Ultimately, such investigation could bring the development of more personalized interventions for the prodromal phase of AD.

Another finding of this study is that the left $\mathrm{HC}$ appeared smaller than the right $\mathrm{HC}$ in aMCI subjects only. Regarding aMCI/D+ and LLD patients, right and left $\mathrm{HC}$ volumes were fairly similar. Again, this can be viewed as additional evidence that aMCI and aMCI/D+ involve, to some extent, distinct pathophysiological mechanisms. Moreover, if we refer to our literature review [73], our results are consistent with the fact that, in $66 \%$ of previous 
aMCI studies [36, 71, 72, 74, 75], volume reduction in the left HC was more important than in the right $\mathrm{HC}$ (for similar conclusions, see also the review by Ries et al. [39] and a metaanalysis by Shi et al. [38]). As for LLD patients, evidence for HC atrophy lateralization is controversial [73], with studies reporting either slightly more important right $\mathrm{HC}$ volume reduction [46, 76-78] or no bilateral differences [79-81], as in the current work. Additional LLD studies are required to clarify whether there is asymmetrical atrophy of the $\mathrm{HC}$ in these patients.

In our study, the aMCI/D+ group had a lower mean MoCA score than aMCI and LLD patients. This difference could first be attributable to the small sample size. It could also be explained by the fact that aMCI/D+ patients have more severe executive deficits [32], and this could have impacted the total MoCA score given the executive load of several items in this instrument. The pathophysiological correlates of executive deficits in aMCI/D+ could involve the presence of cerebrovascular lesions. As a matter of fact, white matter hyperintensities (WMH) are significantly associated with the diagnosis and extent of cerebrovascular lesions [82]. Furthermore, WMH are related to a noticeable decline in global cognitive function [83-87] and to rapid changes in executive function or processing speed [85, 87-89]. Thus, we could make the hypothesis that aMCI/D+ subjects have more WMH than aMCI patients (and possibly LLD patients too). This hypothesis would need to be verified in future studies.

One of the goals of this pilot study was to provide recommendations in order to improve the design of future research aiming to compare the neurobiological characteristics of aMCI, aMCI/D+, and LLD patients. Hence, in our opinion, the following points should be carefully considered in the future: (1) increase the number of participants in each group to detect significant volumetric differences for the right HC, left HC, and right EC; (2) include measures of WMH; (3) include other MRI measures (e.g. parahippocampal or amygdala atrophy, cortical thickness, or diffusion tensor imaging); (4) collect precise information about medications that can have an impact on cognition and brain structures (e.g. selective serotonin reuptake inhibitors); (5) evaluate APOE $\varepsilon 4$ status as we know there is an association between APOE $\varepsilon 4$ and emergent deficits in episodic memory [90]; we could suspect that APOE $\varepsilon 4$ status has an impact on MTL structures; (6) obtain more detailed information about the nature of depressive symptoms in aMCI/D+ in order to clarify their similarities and differences with those of LLD; (7) consider the possibility for LLD patients to meet criteria for aMCI in order to compare 4 groups in a larger study (i.e. aMCI, aMCI/D+, LLD, and LLD/ $\mathrm{MCI}+$ patients); (8) investigate, in each group, other biomarkers of AD such as CSF dosage of $\beta$-amyloid and tau proteins or PET imaging of a myloid load, and (9) conduct longitudinal studies to verify whether the groups of patients differ with regard to the type of dementia (e.g. AD, vascular, or mixed) they eventually develop. Any demonstration of prognostic differences between these groups would reinforce the need to differentiate these syndromes in clinical practice and to develop adapted interventions for each category of patients.

\section{Limitations}

The first limitation of this study relates to the small number of participants, which could explain why our results were not statistically significant. Though, the main findings emphasize the need to investigate aMCI, aMCI/D+, and LLD simultaneously. The second limitation relates to the medication of participants. Five LLD and $5 \mathrm{aMCI} / \mathrm{D}+$ subjects were taking antidepressants, and $1 \mathrm{aMCI} / \mathrm{D}+$ and 2 LLD subjects took benzodiazepines while participating in the study. One should note that benzodiazepines have prominent central effects such as sedation, sleep induction, anxiety reduction, and anterograde amnesia [91, 92]. Moreover, the amnestic effects of benzodiazepines are thought to be mediated by GABA-A receptors containing $\alpha 5$ subunits that are highly expressed in the $\mathrm{HC}$ and related regions [91]. Therefore, 
it appears important to assess benzodiazepine use with more accuracy in future studies because of its possible impact on cognitive functions and, hypothetically, on the classification of subjects. As for antidepressants, about $80 \%$ of aMCI/D+ and LLD participants were taking this medication in the present study. There is growing evidence that long-term antidepressant use may have a positive impact on the HC volume in patients with depression and, therefore, may have a neuroprotective role $[93,94]$. In our study, larger $\mathrm{HC}$ volumes were observed in participants taking antidepressant, i.e. most aMCI/D+ and LLD subjects. Therefore, antidepressants could have partly explained $\mathrm{HC}$ volumetric differences between the groups (aMCI/D+ and LLD vs. aMCI). The third limitation is that delays between neuropsychological evaluation and MRI examination varied from a couple of weeks to several months in certain cases. In future studies, this delay should be reduced as much as possible to diminish the risk of including participants who developed dementia at the time of the MRI examination.

\section{Conclusions}

Previous studies have indicated that aMCI, aMCI/D+, and LLD patients can be distinguished, to a certain extent, by their neuropsychological profiles [32, 33]. To our knowledge, this study is the first to focus on brain volumetric differentiation of these groups. Pre-AD syndromes have heterogeneous presentations and represent an opportunity for potential intervention with disease-modifying therapy [95]. It thus appears critical to further explore the heterogeneous presentations of prodromal AD syndromes and identify biomarkers (such as MTL volumetry and PET imaging of amyloid load and WMH) that could help differentiating and treating prodromal AD conditions.

\section{Acknowledgements}

This work was supported by operating grants from the Ministère du Développement Économique, de l'Innovation et de l'Exportation du Québec, Québec Bio-Imaging Network and Consortium d'imagerie en neurosciences et santé mentale de Québec. S.D. and C.H. are recipients of salary awards from the Fonds de Recherche Québec - Santé. We are very grateful to Drs. Sylvie Belleville, Claire Bouchard, Rémi Bouchard, Pauline Crête, Michel Dugas, Marie-Pier Fortin, Denise Gagné, Jacques Legrand, and Valérie Plante for their help in recruiting participants. We thank Dr. Jens Pruessner from McGill University for his help in the segmentation protocol used in this study. Special thanks to Isabelle Tremblay (Centre de recherche de l'Institut universitaire en santé mentale de Québec, Québec, Qué., Canada) for her collaboration in the participants' assessments.

\section{Disclosure Statement}

The authors have no actual or potential conflicts of interest to declare. 


\section{References}

1 Qiu J: Ticking time bomb faced by China's ageing population. Lancet Neurol 2007;6:582-583.

-2 Morris JC: Early-stage and preclinical Alzheimer disease. Alzheimer Dis Assoc Disord 2005;19:163165.

-3 Palmer K, Fratiglioni L, Winblad B: What is mild cognitive impairment? Variations in definitions and evolution of nondemented persons with cognitive impairment. Acta Neurol Scand Suppl 2003; 179:14-20.

4 Xu G, Meyer JS, Thornby J, Chowdhury M, Quach M: Screening for mild cognitive impairment (MCI) utilizing combined mini-mental-cognitive capacity examinations for identifying dementia prodromes. Int J Geriatr Psychiatry 2002;17:1027-1033.

-5 DeCarli C: Mild cognitive impairment: prevalence, prognosis, aetiology, and treatment. Lancet Neurol 2003;2:15-21.

-6 Petersen RC: Mild cognitive impairment as a diagnostic entity. J Intern Med 2004;256:183-194.

-7 Gauthier S, Reisberg B, Zaudig M, Petersen RC, Ritchie K, Broich K, Belleville S, Brodaty H, Bennett D, Chertkow H, Cummings JL, de Leon M, Feldman H, Ganguli M, Hampel H, Scheltens P, Tierney MC, Whitehouse P, Winblad B: Mild cognitive impairment. Lancet 2006;367:1262-1270.

>8 Petersen RC, Smith GE, Waring SC, Ivnik RJ, Tangalos EG, Kokmen E: Mild cognitive impairment: clinical characterization and outcome. Arch Neurol 1999;56:303-308.

9 American Psychiatric Association: Diagnostic Criteria from DSM-IV-TR. Washington, American Psychiatric Association, 2000.

-10 Panza F, Frisardi V, Capurso C, D’Introno A, Colacicco AM, Imbimbo BP, Santamato A, Vendemiale G, Seripa D, Pilotto A, Capurso A, Solfrizzi V: Late-life depression, mild cognitive impairment, and dementia: possible continuum? Am J Geriatr Psychiatry 2010;18:98-116.

- 11 Lockwood KA, Alexopoulos GS, Kakuma T, Van Gorp WG: Subtypes of cognitive impairment in depressed older adults. Am J Geriatr Psychiatry 2000;8:201-208.

$\checkmark 12$ Elderkin-Thompson V, Kumar A, Mintz J, Boone K, Bahng E, Lavretsky H: Executive dysfunction and visuospatial ability among depressed elders in a community setting. Arch Clin Neuropsychol 2004;19:597-611.

-13 Geda YE, Knopman DS, Mrazek DA, Jicha GA, Smith GE, Negash S, Boeve BF, Ivnik RJ, Petersen RC, Pankratz VS, Rocca WA: Depression, apolipoprotein E genotype, and the incidence of mild cognitive impairment: a prospective cohort study. Arch Neurol 2006;63:435-440.

-14 Byers AL, Yaffe K: Depression and risk of developing dementia. Nat Rev Neurol 2011;7:323-331.

-15 Saczynski JS, Beiser A, Seshadri S, Auerbach S, Wolf PA, Au R: Depressive symptoms and risk of dementia: the Framingham Heart Study. Neurology 2010;75:35-41.

-16 Andersen K, Lolk A, Kragh-Sorensen P, Petersen NE, Green A: Depression and the risk of Alzheimer disease. Epidemiology 2005; 16:233-238.

17 Gatz JL, Tyas SL, St John P, Montgomery P: Do depressive symptoms predict Alzheimer's disease and dementia? J Gerontol A Biol Sci Med Sci 2005;60:744-747.

-18 Chen R, Hu Z, Wei L, Qin X, McCracken C, Copeland JR: Severity of depression and risk for subsequent dementia: cohort studies in China and the UK. Br J Psychiatry 2008;193:373-377.

19 Byers AL, Covinsky KE, Barnes DE, Yaffe K: Dysthymia and depression increase risk of dementia and mortality among older veterans. Am J Geriatr Psychiatry 2012;20:664-672.

-20 Hebert R, Lindsay J, Verreault R, Rockwood K, Hill G, Dubois MF: Vascular dementia: incidence and risk factors in the Canadian study of health and aging. Stroke 2000;31:1487-1493.

-21 Apostolova LG, Cummings JL: Neuropsychiatric manifestations in mild cognitive impairment: a systematic review of the literature. Dement Geriatr Cogn Disord 2008;25:115-126.

-22 Beaulieu-Bonneau S, Hudon C: Sleep disturbances in older adults with mild cognitive impairment. Int Psychogeriatr 2009;21:654-666.

-23 Steffens DC, Otey E, Alexopoulos GS, Butters MA, Cuthbert B, Ganguli M, Geda YE, Hendrie HC, Krishnan RR, Kumar A, Lopez OL, Lyketsos CG, Mast BT, Morris JC, Norton MC, Peavy GM, Petersen RC, Reynolds CF, Salloway S, Welsh-Bohmer KA, Yesavage J: Perspectives on depression, mild cognitive impairment, and cognitive decline. Arch Gen Psychiatry 2006;63:130-138.

24 Ilsley JE, Moffoot AP, O'Carroll RE: An analysis of memory dysfunction in major depression. J Affect Disord 1995;35:1-9. 
25 Belleville S, Sylvain-Roy S, de Boysson C, Menard MC: Characterizing the memory changes in persons with mild cognitive impairment. Prog Brain Res 2008;169:365-375.

26 Morin JF, Hudon C, Duchesne S: Medial temporal lobe volumes in amnestic mild cognitive impairment and late-life depression: Reserch synthesis. Curr Psychiatry Rev 2012, in press.

-27 Simard M, Hudon C, van Reekum R: Psychological distress and risk for dementia. Curr Psychiatry Rep 2009;11:41-47.

-28 Lu PH, Edland SD, Teng E, Tingus K, Petersen RC, Cummings JL: Donepezil delays progression to AD in MCI subjects with depressive symptoms. Neurology 2009;72:2115-2121.

-29 Teng E, Lu PH, Cummings JL: Neuropsychiatric symptoms are associated with progression from mild cognitive impairment to Alzheimer's disease. Dement Geriatr Cogn Disord 2007;24:253259.

-30 Modrego PJ, Ferrandez J: Depression in patients with mild cognitive impairment increases the risk of developing dementia of Alzheimer type: a prospective cohort study. Arch Neurol 2004;61:12901293.

-31 Lee GJ, Lu PH, Hua X, Lee S, Wu S, Nguyen K, Teng E, Leow AD, Jack CR Jr, Toga AW, Weiner MW, Bartzokis G, Thompson PM: Depressive symptoms in mild cognitive impairment predict greater atrophy in Alzheimer's disease-related regions. Biol Psychiatry 2012;71:814-821.

- 32 Hudon C, Belleville S, Gauthier S: The association between depressive and cognitive symptoms in amnestic mild cognitive impairment. Int Psychogeriatr 2008;20:710-723.

-33 Brunet J, Hudon C, Macoir J, Belleville S, Rousseau F, Bouchard RW, Verret L, Chertkow H, Chayer C, Kergoat MJ, Joubert S: The relation between depressive symptoms and semantic memory in amnestic mild cognitive impairment and in late-life depression. J Int Neuropsychol Soc 2011;17:865874.

- 34 Dubois B, Feldman HH, Jacova C, Dekosky ST, Barberger-Gateau P, Cummings J, Delacourte A, Galasko D, Gauthier S, Jicha G, Meguro K, O’Brien J, Pasquier F, Robert P, Rossor M, Salloway S, Stern Y, Visser PJ, Scheltens P: Research criteria for the diagnosis of Alzheimer's disease: revising the NINCDS-ADRDA criteria. Lancet Neurol 2007;6:734-746.

- 35 Braak H, Braak E: Neuropathological stageing of Alzheimer-related changes. Acta Neuropathol 1991; 82:239-259.

-36 Pennanen C, Kivipelto M, Tuomainen S, Hartikainen P, Hanninen T, Laakso MP, Hallikainen M, Vanhanen M, Nissinen A, Helkala EL, Vainio P, Vanninen R, Partanen K, Soininen H: Hippocampus and entorhinal cortex in mild cognitive impairment and early AD. Neurobiol Aging 2004;25:303310.

-37 Laakso MP, Frisoni GB, Kononen M, Mikkonen M, Beltramello A, Geroldi C, Bianchetti A, Trabucchi M, Soininen H, Aronen HJ: Hippocampus and entorhinal cortex in frontotemporal dementia and Alzheimer's disease: a morphometric MRI study. Biol Psychiatry 2000;47:1056-1063.

-38 Shi F, Liu B, Zhou Y, Yu C, Jiang T: Hippocampal volume and asymmetry in mild cognitive impairment and Alzheimer's disease: meta-analyses of MRI studies. Hippocampus 2009;19:1055-1064.

-39 Ries ML, Carlsson CM, Rowley HA, Sager MA, Gleason CE, Asthana S, Johnson SC: Magnetic resonance imaging characterization of brain structure and function in mild cognitive impairment: a review. J Am Geriatr Soc 2008;56:920-934.

-40 Wolf H, Grunwald M, Kruggel F, Riedel-Heller SG, Angerhofer S, Hojjatoleslami A, Hensel A, Arendt T, Gertz H: Hippocampal volume discriminates between normal cognition; questionable and mild dementia in the elderly. Neurobiol Aging 2001;22:177-186.

-41 Duchesne S, Caroli A, Geroldi C, Collins DL, Frisoni GB: Relating one-year cognitive change in mild cognitive impairment to baseline MRI features. Neuroimage 2009;47:1363-1370.

-42 Jack CR, Jr., Shiung MM, Gunter JL, O’Brien PC, Weigand SD, Knopman DS, Boeve BF, Ivnik RJ, Smith GE, Cha RH, Tangalos EG, Petersen RC: Comparison of different MRI brain atrophy rate measures with clinical disease progression in AD. Neurology 2004;62:591-600.

-43 Dickerson BC, Goncharova I, Sullivan MP, Forchetti C, Wilson RS, Bennett DA, Beckett LA, deToledo-Morrell L: MRI-derived entorhinal and hippocampal atrophy in incipient and very mild Alzheimer's disease. Neurobiol Aging 2001;22:747-754.

-44 de Leon M, Bobinski M, Convit A, Wolf O, Insausti R: Usefulness of MRI measures of entorhinal cortex versus hippocampus in AD. Neurology 2001;56:820-821.

-45 Raz N, Rodrigue KM, Head D, Kennedy KM, Acker JD: Differential aging of the medial temporal lobe: a study of a five-year change. Neurology 2004;62:433-438. 
-46 Steffens DC, Byrum CE, McQuoid DR, Greenberg DL, Payne ME, Blitchington TF, MacFall JR, Krishnan KR: Hippocampal volume in geriatric depression. Biol Psychiatry 2000;48:301-309.

Morin JF, Hudon C, Duchesne S: Hippocampal and entorhinal volumetry in amnestic mild cognitive impairment and late-life depression. International Conference on Alzheimer's Disease 2010. Honolulu, Alzheimer's Association, 2010.

-48 Killiany RJ, Hyman BT, Gomez-Isla T, Moss MB, Kikinis R, Jolesz F, Tanzi R, Jones K, Albert MS: MRI measures of entorhinal cortex vs hippocampus in preclinical AD. Neurology 2002;58:11881196.

-49 deToledo-Morrell L, Stoub TR, Bulgakova M, Wilson RS, Bennett DA, Leurgans S, Wuu J, Turner DA: MRI-derived entorhinal volume is a good predictor of conversion from MCI to AD. Neurobiol Aging 2004;25:1197-1203.

-50 Dierckx E, Engelborghs S, De Raedt R, De Deyn PP, Ponjaert-Kristoffersen I: Mild cognitive impairment: what's in a name? Gerontology 2007;53:28-35.

-51 Yesavage JA, Brink TL, Rose TL, Lum O, Huang V, Adey M, Leirer VO: Development and validation of a geriatric depression screening scale: a preliminary report. J Psychiatr Res 1982;17:37-49.

-52 Debruyne H, Van Buggenhout M, Le Bastard N, Aries M, Audenaert K, De Deyn PP, Engelborghs S: Is the geriatric depression scale a reliable screening tool for depressive symptoms in elderly patients with cognitive impairment? Int J Geriatr Psychiatry 2009;24:556-562.

-53 Hachinski VC, Iliff LD, Zilhka E, Du Boulay GH, McAllister VL, Marshall J, Russell RW, Symon L: Cerebral blood flow in dementia. Arch Neurol 1975;32:632-637.

-54 Nasreddine ZS, Phillips NA, Bedirian V, Charbonneau S, Whitehead V, Collin I, Cummings JL, Chertkow H: The Montreal Cognitive Assessment, MoCA: a brief screening tool for mild cognitive impairment. J Am Geriatr Soc 2005;53:695-699.

55 Thomas-Anterion C, Ribas C, Honoré-Masson S, Berne G, Ruel JH, Laurent B: Le questionnaire de plainte cognitive (qpc): Un outil de recherche de plainte suspecte d'voquer une maladie d'alzheimer. L’Année gérontologique 2003;17:56-65.

56 van der Linden M, Adam S, Agniel A, Baisset-Mouly C, Bardet F, Coyette F: L'évaluation des troubles de la mémoire. Présentation de quatre tests de mémoire épisodique (avec leur étalonnage). Marseilles, Solal, 2004.

-57 Grober E, Buschke H, Crystal H, Bang S, Dresner R: Screening for dementia by memory testing. Neurology 1988;38:900-903.

58 Rey A: Test de copie et reproduction de mémoire de figures géométriques complexes. Paris, Centre de Psychologie Appliquée, 1970.

59 Riddoch MJ, Humphreys GW: Birmingham Object Recognition Battery (BORB). Hillsdale, Lawrence Erlbaum Associates Publishers, 1993.

60 Wechsler D: Wechsler Adult Intelligence Scale-III (WAIS-III). San Antonio, The Psychological Corporation, 1997.

61 Consortium des Universités de Montréal et McGill: Manuel de l'examen neuropsychologique: Étude Santé et Vieillissement au Canada. Montréal, 1996.

-62 Calero MD, Arnedo ML, Navarro E, Ruiz-Pedrosa M, Carnero C: Usefulness of a 15-item version of the Boston Naming Test in neuropsychological assessment of low-educational elders with dementia. J Gerontol B Psychol Sci Soc Sci 2002;57:P187-P191.

63 Howard D, Partterson K: The Pyramids and Palm Trees Test. A Test of Semantic Access from Words and Pictures. St. Edmunds, Thames Valley Company, 1992.

64 Delis DC, Kramer J, Kaplan E: The Delis-Kaplan Executive Function System Manual. San Antonio, The Psychological Corporation, 2001.

-65 Galasko D, Bennett D, Sano M, Ernesto C, Thomas R, Grundman M, Ferris S: An inventory to assess activities of daily living for clinical trials in Alzheimer's disease. The Alzheimer's Disease Cooperative Study. Alzheimer Dis Assoc Disord 1997;11(suppl 2):S33-S39.

-66 Jack CR Jr, Bernstein MA, Fox NC, Thompson P, Alexander G, Harvey D, Borowski B, Britson PJ, J LW, Ward C, Dale AM, Felmlee JP, Gunter JL, Hill DL, Killiany R, Schuff N, Fox-Bosetti S, Lin C, Studholme C, DeCarli CS, Krueger G, Ward HA, Metzger GJ, Scott KT, Mallozzi R, Blezek D, Levy J, Debbins JP, Fleisher AS, Albert M, Green R, Bartzokis G, Glover G, Mugler J, Weiner MW: The Alzheimer's Disease Neuroimaging Initiative (ADNI): MRI methods. J Magn Reson Imaging 2008; 27:685-691. 
67 Fonov V, Evans A, McKinstry R, Almli C, Collins D: Unbiased nonlinear average age-appropriate brain templates from birth to adulthood neuroimage. Organization for Human Brain Mapping 2009 Annual Meeting. San Francisco, 2009, vol 47(suppl 1), p S102.

-68 Pruessner JC, Li LM, Serles W, Pruessner M, Collins DL, Kabani N, Lupien S, Evans AC: Volumetry of hippocampus and amygdala with high-resolution MRI and three-dimensional analysis software: minimizing the discrepancies between laboratories. Cereb Cortex 2000;10:433-442.

-69 Pruessner JC, Kohler S, Crane J, Pruessner M, Lord C, Byrne A, Kabani N, Collins DL, Evans AC: Volumetry of temporopolar, perirhinal, entorhinal and parahippocampal cortex from high-resolution MR images: considering the variability of the collateral sulcus. Cereb Cortex 2002;12:13421353.

-70 Bruce JM, Bhalla R, Westervelt HJ, Davis J, Williams V, Tremont G: Neuropsychological correlates of self-reported depression and self-reported cognition among patients with mild cognitive impairment. J Geriatr Psychiatry Neurol 2008;21:34-40.

-71 Jessen F, Feyen L, Freymann K, Tepest R, Maier W, Heun R, Schild HH, Scheef L: Volume reduction of the entorhinal cortex in subjective memory impairment. Neurobiol Aging 2006;27:1751-1756.

-72 Du AT, Schuff N, Amend D, Laakso MP, Hsu YY, Jagust WJ, Yaffe K, Kramer JH, Reed B, Norman D, Chui HC, Weiner MW: Magnetic resonance imaging of the entorhinal cortex and hippocampus in mild cognitive impairment and Alzheimer's disease. J Neurol Neurosurg Psychiatry 2001;71:441447.

-73 Morin JF, Hudon C, Duchesne S: Hippocampal and entorhinal volumetry in amnestic mild cognitive impairment and late-life depression. Alzheimers Dement 2010;6:S419-S420.

-74 Morra JH, Tu Z, Apostolova LG, Green AE, Avedissian C, Madsen SK, Parikshak N, Hua X, Toga AW, Jack CR Jr, Schuff N, Weiner MW, Thompson PM: Automated 3D mapping of hippocampal atrophy and its clinical correlates in 400 subjects with Alzheimer's disease, mild cognitive impairment, and elderly controls. Hum Brain Mapp 2009;30:2766-2788.

-75 Wang PN, Lirng JF, Lin KN, Chang FC, Liu HC: Prediction of Slzheimer's disease in mild cognitive impairment: a prospective study in Taiwan. Neurobiol Aging 2006;27:1797-1806.

-76 Ballmaier M, Kumar A, Thompson PM, Narr KL, Lavretsky H, Estanol L, Deluca H, Toga AW: Localizing gray matter deficits in late-onset depression using computational cortical pattern matching methods. Am J Psychiatry 2004;161:2091-2099.

-77 Lloyd AJ, Ferrier IN, Barber R, Gholkar A, Young AH, O’Brien JT: Hippocampal volume change in depression: late- and early-onset illness compared. Br J Psychiatry 2004;184:488-495.

-78 O’Brien JT, Lloyd A, McKeith I, Gholkar A, Ferrier N: A longitudinal study of hippocampal volume, cortisol levels, and cognition in older depressed subjects. Am J Psychiatry 2004;161:2081-2090.

-79 Ashtari M, Greenwald BS, Kramer-Ginsberg E, Hu J, Wu H, Patel M, Aupperle P, Pollack S: Hippocampal/amygdala volumes in geriatric depression. Psychol Med 1999;29:629-638.

-80 Qiu A, Taylor WD, Zhao Z, MacFall JR, Miller MI, Key CR, Payne ME, Steffens DC, Krishnan KR: APOE related hippocampal shape alteration in geriatric depression. Neuroimage 2009;44:620-626.

-81 Taylor WD, Steffens DC, Payne ME, MacFall JR, Marchuk DA, Svenson IK, Krishnan KR: Influence of serotonin transporter promoter region polymorphisms on hippocampal volumes in late-life depression. Arch Gen Psychiatry 2005;62:537-544.

-82 Yoshita M, Fletcher E, Harvey D, Ortega M, Martinez O, Mungas DM, Reed BR, DeCarli CS: Extent and distribution of white matter hyperintensities in normal aging, MCI, and AD. Neurology 2006; 67:2192-2198.

-83 Appelros P, Samuelsson M, Lindell D: Lacunar infarcts: functional and cognitive outcomes at five years in relation to MRI findings. Cerebrovasc Dis 2005;20:34-40.

$\$ 84$ Dufouil C, Godin O, Chalmers J, Coskun O, MacMahon S, Tzourio-Mazoyer N, Bousser MG, Anderson C, Mazoyer B, Tzourio C: Severe cerebral white matter hyperintensities predict severe cognitive decline in patients with cerebrovascular disease history. Stroke 2009;40:2219-2221.

- 85 Jokinen H, Kalska H, Ylikoski R, Madureira S, Verdelho A, van der Flier WM, Scheltens P, Barkhof F, Visser MC, Fazekas F, Schmidt R, O’Brien J, Waldemar G, Wallin A, Chabriat H, Pantoni L, Inzitari D, Erkinjuntti T: Longitudinal cognitive decline in subcortical ischemic vascular disease - the LADIS study. Cerebrovasc Dis 2009;27:384-391. 
-86 van der Flier WM, van der Vlies AE, Weverling-Rijnsburger AW, de Boer NL, Admiraal-Behloul F, Bollen EL, Westendorp RG, van Buchem MA, Middelkoop HA: MRI measures and progression of cognitive decline in nondemented elderly attending a memory clinic. Int J Geriatr Psychiatry 2005; 20:1060-1066.

-87 Debette S, Bombois S, Bruandet A, Delbeuck X, Lepoittevin S, Delmaire C, Leys D, Pasquier F: Subcortical hyperintensities are associated with cognitive decline in patients with mild cognitive impairment. Stroke 2007;38:2924-2930.

-88 Mungas D, Harvey D, Reed BR, Jagust WJ, DeCarli C, Beckett L, Mack WJ, Kramer JH, Weiner MW, Schuff N, Chui HC: Longitudinal volumetric MRI change and rate of cognitive decline. Neurology 2005;65:565-571.

-89 van den Heuvel DM, ten Dam VH, de Craen AJ, Admiraal-Behloul F, Olofsen H, Bollen EL, Jolles J, Murray HM, Blauw GJ, Westendorp RG, van Buchem MA: Increase in periventricular white matter hyperintensities parallels decline in mental processing speed in a non-demented elderly population. J Neurol Neurosurg Psychiatry 2006;77:149-153.

-90 Bondi MW, Salmon DP, Monsch AU, Galasko D, Butters N, Klauber MR, Thal LJ, Saitoh T: Episodic memory changes are associated with the APOE-epsilon 4 allele in nondemented older adults. Neurology 1995;45:2203-2206.

-91 Nutt DJ, Stahl SM: Searching for perfect sleep: the continuing evolution of GABAA receptor modulators as hypnotics. J Psychopharmacol 2010;24:1601-1612.

-92 Vermeeren A, Coenen AM: Effects of the use of hypnotics on cognition. Prog Brain Res 2011;190: 89-103.

-93 Malykhin NV, Carter R, Seres P, Coupland NJ: Structural changes in the hippocampus in major depressive disorder: contributions of disease and treatment. J Psychiatry Neurosci 2010;35:337-343.

$\checkmark 94$ Dhikav V, Anand KS: Is hippocampal atrophy a future drug target? Med Hypotheses 2007;68:13001306.

-95 Sperling RA, Aisen PS, Beckett LA, Bennett DA, Craft S, Fagan AM, Iwatsubo T, Jack CR Jr, Kaye J, Montine TJ, Park DC, Reiman EM, Rowe CC, Siemers E, Stern Y, Yaffe K, Carrillo MC, Thies B, Morrison-Bogorad M, Wagster MV, Phelps CH: Toward defining the preclinical stages of Alzheimer's disease: recommendations from the National Institute on Aging-Alzheimer's Association workgroups on diagnostic guidelines for Alzheimer's disease. Alzheimers Dement 2011;7:280-292. 